\title{
The Distribution of Aspartic Acid Residues in Bovine Dentine Phosphoprotein
}

\author{
Ronald D. Krippner and Charles F. Nawrot* \\ Department of Oral Biology and Dental Research Institute, The University of Michigan, \\ Ann Arbor, Michigan 48109, USA
}

Recently, Weiner and Hood (Science 190:987989,1975 ) reported the use of an acid hydrolysis procedure in the study of the aspartic acid linkages of the soluble protein of the organic matrix of mollusk shells. Peptide bonds on both sides of aspartic acid residues have been shown to be particularly labile to hydrolysis by dilute acetic or hydrochloric acids (SGHULtz et al, Biochemistry 1:694-698, 1962; LeAGH, in Proc. Internat. Wool Textile Res. Conf., Pt I, CSIRO, Melbourne, Australia, p. C185, 1955). By following the release of aspartic acid and other amino acids, particularly serine and glycine, these workers were able to conclude that the repeating sequence (ASP-Y) is a common occurrence in mollusk shell proteins.

This report deals with the application of this dilute acid hydrolysis to a very similar protein derived from bovine dentin matrix. Phosphoprotein was isolated from unerupted bovine molars by EDTA extraction and separation on hydroxyapatite columns (NAWROT et al, Biochemistry 15:3445-3449, 1976). This protein has been shown to contain $7 \%$ phosphorus with $3 / 4$ of its amino acids as serine and aspartic acid. The liberation of aspartic acid and other amino acids by $0.25 M$ acetic acid in vacuo at 110 $\mathrm{C}$ was followed using the amino acid analyzer. The figure gives the results at various time intervals from 18-120 hours for the release of aspartic acid, serine, and all amino acids. At 120 hours, $47 \%$ of all possible amino acid residues were released. Aspartic acid and serine residues combined made up $90 \%$ of the residues which were released after 120 hours. Based on the aspartic acid content of the protein estimated by complete acid hydrolysis in $\mathrm{HCl} \times$ $4.6 \times 10^{-1} \mu$ mole $\mathrm{mg}^{-1}$, the acetic acid released $80 \%$ of the total aspartic acid. Only small amounts of other amino acids $\left(<2 \times 10^{-2}\right.$ $\mu$ mole $\cdot \mathrm{mg}^{-1}$ ) were released during this time.

In order to account for the release of serine and amino acids other than aspartic acid, approximately half of the total aspartic acid must occur in sequences of the type (ASP-Y) n, where

Received for publication July 27, 1976.

Accepted for publication September 17, 1976.

This investigation was supported by USPHS Grant Nos. AM-19385 and DE-04538.

* For reprints.
$\mathrm{Y}$ is not aspartic acid. This estimate is based on the fact that only aspartic acid linkages are cleaved by this mild procedure and the amount of other amino acids released at 120 hours (2.3 $\times 10^{-1} \mu \mathrm{mole} \cdot \mathrm{mg}^{-1}$ or approximately half the amount of total aspartate). The data further support the frequent occurrence of serine or serine phosphate in position $Y$.

Glearly, the regular amino acid pattern of this protein may be important to its role in mineralization. Weinstoak and Lebold ( $J$ Cell Biol $56: 838-845,1973$ ) have provided evidence for the involvement of a serine rich phosphoprotein in the mineralization of rat incisor dentin. Sequencing studies on the dentin phosphoproteins should shed more light on how it carries out its biological function.

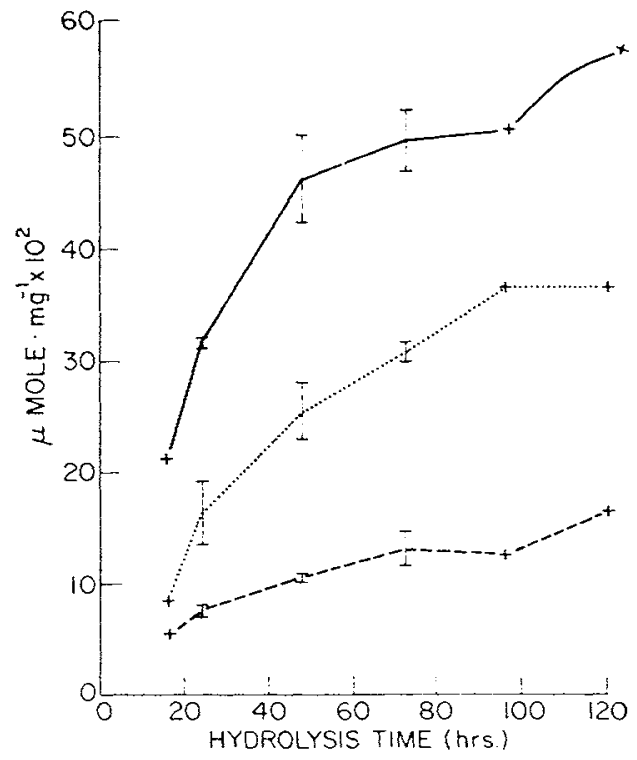

Fig.-Amino acids (___ all amino acids, ..... aspartic acid, ----- serine) released at various times by hydrolysis of bovine dentin phosphoprotein in $0.25 M$ acetic acid. Variations in duplicate analyses are indicated. 